\section{(1) \\ CrossMark}

\title{
Digital health to end tuberculosis in the Sustainable Development Goals era: achievements, evidence and future perspectives
}

\author{
Dennis Falzon ${ }^{1}$, Giovanni Battista Migliori (10,3 ${ }^{2,3}$ Ernesto Jaramillo ${ }^{1}$, \\ Karin Weyer ${ }^{1}$, Guy Joos ${ }^{2}$ and Mario Raviglione ${ }^{1}$ on behalf of the Global Task \\ Force on digital health for $\mathrm{TB}^{4}$
}

\begin{abstract}
Affiliations: ${ }^{1}$ World Health Organization, Global TB Programme, Geneva, Switzerland. ${ }^{2}$ European Respiratory Society, Lausanne, Switzerland. ${ }^{3}$ World Health Organization Collaborating Centre for TB and Lung Diseases, Maugeri Care and Research Institute, Tradate, Italy. ${ }^{4}$ For a list of the members of the Global Task Force on digital health for TB see the Acknowledgements.
\end{abstract}

Correspondence: Dennis Falzon, World Health Organization, Global TB Programme, 20 avenue Appia, Geneva, $\mathrm{CH}-1211$, Switzerland. E-mail: falzondawho.int

@ERSpublications

Use of digital technologies to support TB care and prevention can be a model for broader action to achieve the SDGs http://ow.ly/QEcE30fKnAZ

Cite this article as: Falzon D, Migliori GB, Jaramillo E, et al. Digital health to end tuberculosis in the Sustainable Development Goals era: achievements, evidence and future perspectives. Eur Respir J 2017; 50: 1701632 [https://doi.org/10.1183/13993003.01632-2017].

Until 2015, the United Nations Millennium Development Goals provided a framework for countries to work towards targets aimed at improving health. Major progress was achieved globally as a result of this drive. Important challenges, however, persist for both communicable (e.g. tuberculosis (TB) and HIV) and noncommunicable (e.g. tobacco use) health problems. The Sustainable Development Goals (SDGs), which now guide the global development agenda until 2030, approach these health problems more holistically [1]. The "integrated and indivisible" nature of the SDGs requires action across all layers of society. To achieve the health-specific Goal 3 ("Ensure healthy lives and promote well-being for all at all ages"), countries also need to act on the other 16 SDGs, such as poverty (Goal 1), malnutrition (Goal 2), gender-associated inequalities (Goal 5), investment in information and communications technology and in research by the public and private sectors (Goal 9), transparency, accountability and nondiscriminatory laws (Goal 16), and cross-sectoral collaboration and partnerships (Goal 17).

This editorial highlights how digital technologies can be key accessories to the attainment of SDG targets critical for health, as patients and caregivers worldwide depend increasingly on internet and computing for

Received: Aug 092017 | Accepted after revision: Sept 122017

Support statement: European Respiratory Society (ERS-WHO Agreement Phase 3 2017-2018). Funding information for this article has been deposited with the Crossref Funder Registry.

Conflict of interest: Disclosures can be found alongside this article at erj.ersjournals.com

D. Falzon, E. Jaramillo, K. Weyer and M. Raviglione are staff members of the World Health Organization (WHO). They alone are responsible for the views expressed in this publication and they do not necessarily represent the decisions or policies of WHO. The designations used and the presentation of the material in this publication do not imply the expression of any opinion whatsoever on the part of WHO concerning the legal status of any country, territory, city or area, or of its authorities, nor concerning the delimitation of its frontiers or boundaries. 


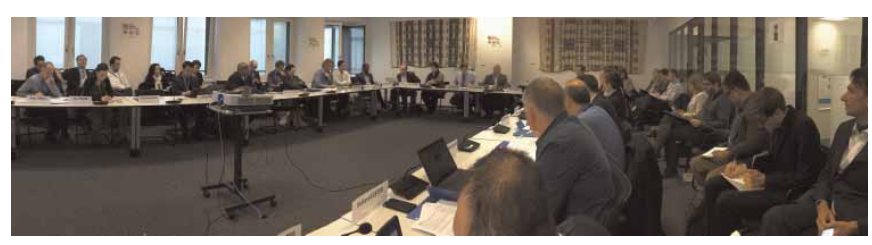

FIGURE 1 World Health Organization/European Respiratory Society technical consultation on digital health for tuberculosis (February 7-8, 2017).

daily activities. For instance, within Goal 3 itself, digital technologies could enhance the delivery of information needed to train the health workforce (target 3.c), to prevent disease and enable healthy behaviours (targets 3.a and 3.4), and to increase access to essential healthcare services and goods (target 3.8). These interventions commonly involve "apps" on mobile devices to help patients and healthcare providers communicate via voice, text or video to improve treatment adherence, to allow clinicians to access medical records and to deliver electronic learning (e.g. on clinical guidelines).

TB, the leading single infectious cause of death in the world (1.8 million estimated deaths in 2015 [2]) has its determinants firmly rooted in social and health factors. It thus provides an illustrative example of how digital health interventions targeting a major disease need to be inclusive and adopt a multisector approach to prevention and care. Apart from the benefit that digital interventions can have on efforts to curb TB more effectively and efficiently, they could also serve as a "flagship" for other disease programmes to follow given the ubiquity of TB in global geography and in many aspects of public health. In 2014, the World Health Organization (WHO) elaborated its End TB Strategy in response to a World Health Assembly Resolution urging Member States to end the worldwide epidemic of TB by 2035 [3]. Similarly to the SDGs, to which it is aligned, the End TB Strategy requires novel approaches to be implemented broadly for its ambitious objectives to be realised [4]. Digital technologies play a pivotal role on different fronts in helping achieve these targets, such as in helping patients and carers improve the treatment experience or to automate the management of health information. In 2015, the WHO Global TB Programme, the European Respiratory Society and a task force of global experts (see Acknowledgements) developed a collaborative agenda for action to promote the wider use of digital health in support of the End TB Strategy [5]. Target product profiles were produced that describe the essential features that priority concepts in digital health must have to enhance patient care, surveillance, programme management or human resource development [6].

Over the past decades, patients and caregivers have benefited variably from digital technologies to combat TB. Unprecedented investment in electronic solutions has occurred, in particular for the recording of disaggregated data for TB surveillance, for connecting diagnostic devices and to support patients on TB treatment. These have been successfully scaled up even in large countries like India and China with a large burden of TB [7, 8]. While several of these endeavours have borne results, many have not been implemented sustainably at a large scale. Evidence of impact has often been inconclusive, context-specific or narrow in scope (e.g. focused on effectiveness more than quality of life and patient-important dimensions). This limits its extrapolation to settings with conditions that deviate from those where the studies were conducted. The knowledge base is nonetheless steadily growing, and will hopefully help practitioners decide when and how best to apply such technologies [9-13].

Healthcare practice appears to be on the cusp of a transformative change. Disruptive technological developments, such as personalised medicine, and the integration of artificial intelligence and machine learning into clinical tools, are on the horizon [14]. Continued advances in both software performance as well as access to broadband internet and hardware are destined to benefit more people worldwide. These concurrent developments will make digital interventions more scalable via mobile electronic devices, across all dimensions mapped out by the digital "agenda for action" for TB [5]. Products created to improve tuberculosis patient care, surveillance, programme management or human resource development could be adapted to the management of other health conditions.

However, unless access to the internet in low-resource settings and in rural areas improves, there is a risk that today's societal inequities become entrenched even further, forfeiting much of the "digital dividends" that could be reaped $[15,16]$. The roll-out of game-changing technologies will also make new demands for appropriate legal and infrastructural frameworks to address security, privacy, access and management of confidential data.

Digital health for TB is expected to feature prominently in a landmark ministerial conference titled "A Multisectoral Response to Ending TB in the Sustainable Development Era”, being held in the Russian 
Federation in November 2017 ahead of a high-level meeting of the United Nations General Assembly on the same theme in 2018 [17]. Bold outcomes are anticipated from these meetings. Amongst others, these could include the creation of a "facility" to catalyse the further development and large-scale implementation of innovative digital technologies matched to the health priorities of national programmes, and the promotion of research on their impact. Such radical change will be critical to achieve the targets of the End TB Strategy and the SDGs.

\section{Acknowledgements}

The authors acknowledge the contribution to the arguments presented in this article of the Global Task Force on digital health for TB, chaired by Giovanni Battista Migliori (WHO Collaborating Centre for TB and Lung Diseases, Maugeri Care and Research Institute, Tradate, Italy), and composed of Andrei Dadu (WHO Regional Office for Europe, Copenhagen, Denmark), Claudia Denkinger (FIND, Geneva, Switzerland), Luis Gustavo do Valle Bastos (Global Drug Facility, Geneva, Switzerland), Richard Garfein (University of California San Diego, San Diego, CA, USA), Richard Lester (University of British Columbia, Vancouver, Canada), Kirankumar Rade (Revised National TB Control Programme, New Delhi, India), Lal Sadasivan (PATH, Washington, DC, USA), Kaiser Shen (USAID, Washington, DC, USA), Alena Skrahina (National TB Programme, Minsk, Belarus), Giovanni Sotgiu (University of Sassari, Sassari, Italy), Alistair Story (Find \& Treat, London, UK), Khin Swe Win (Myanmar Medical Association, Yangon, Myanmar), Zelalem Temesgen (Mayo Clinic, Rochester, MN, USA), Bruce V. Thomas (The Arcady Group, Richmond, VA, USA), Kristian van Kalmthout (KNCV Tuberculosis Foundation, The Hague, The Netherlands), Arne von Delft (TB PROOF, Cape Town, South Africa) and Mohammed Yassin (Global Fund to Fight AIDS, TB and Malaria, Geneva, Switzerland). This editorial also draws on some of the discussions at a WHO/ERS consulation held in February 2017 [18] (figure 1).

\section{References}

1 United Nations Department of Economic and Social Affairs. Sustainable Development Goals. https:// sustainabledevelopment.un.org/sdgs Date last updated: 2015.

2 World Health Organization. Global tuberculosis report 2016 (WHO/HTM/TB/2016.13). http://apps.who.int/iris/ bitstream/10665/250441/1/9789241565394-eng.pdf Date last updated: 2016.

3 Sixty-seventh World Health Assembly. Resolution WHA67.1. Global strategy and targets for tuberculosis prevention, care and control after 2015. http://apps.who.int/gb/ebwha/pdf_files/WHA67/A67_R1-en.pdf Date last updated: May 21, 2014.

4 World Health Organization. Implementing the End TB Strategy: the essentials (WHO/HTM/TB/2015.31). www. who.int/tb/publications/2015/end_tb_essential.pdf Date last updated: 2015.

5 World Health Organization, European Respiratory Society. Digital health for the End TB Strategy: an agenda for action (WHO/HTM/TB/2015.21). http://apps.who.int/iris/bitstream/10665/205222/1/WHO_HTM_TB_2015.21_ eng.pdf Date last updated: 2015

6 Falzon D, Timimi H, Kurosinski P, et al. Digital health for the End TB Strategy: developing priority products and making them work. Eur Respir J 2016; 48: 29-45.

7 Revised National Tuberculosis Programme. NIKSHAY - A Web Based Solution for Monitoring of TB Patients. http://nikshay.gov.in/AboutNikshay.htm Date last accessed: July 17, 2015.

8 Huang $\mathrm{F}$, Cheng $\mathrm{S}, \mathrm{Du} \mathrm{X}$, et al. Electronic recording and reporting system for tuberculosis in China: experience and opportunities. J Am Med Inform Assoc 2014; 21: 938-941.

9 Nglazi MD, Bekker L-G, Wood R, et al. Mobile phone text messaging for promoting adherence to anti-tuberculosis treatment: a systematic review. BMC Infect Dis 2013; 13: 566.

10 Liu $\mathrm{X}$, Lewis JJ, Zhang $\mathrm{H}$, et al. Effectiveness of electronic reminders to improve medication adherence in tuberculosis patients: a cluster-randomised trial. PLoS Med 2015; 12: e1001876.

11 Story A, Garfein RS, Hayward A, et al. Monitoring therapy adherence of tuberculosis patients by using video-enabled electronic devices. Emerg Infect Dis 2016; 22: 538-540.

12 Sinkou $\mathrm{H}$, Hurevich $\mathrm{H}$, Rusovich V, et al. Video-observed treatment for tuberculosis patients in Belarus: findings from the first programmatic experience. Eur Respir J 2017; 49: 1602049.

13 Ngwatu BK, Nsengiyumva P, Oxlade O, et al. The impact of digital health technologies on tuberculosis treatment adherence and outcomes: a systematic literature review. Eur Respir J 2017; in press [https://doi.org/10.1183/ 13993003.01596-2017].

14 Falzon D, Raviglione M. The Internet of Things to come: digital technologies and the End TB Strategy. BMJ Glob Health 2016; 1: e000038.

15 Alliance for Affordable Internet. 2017 Affordability Report. http://1e8q3q16vyc81g8l3h3md6q5f5e.wpengine. netdna-cdn.com/wp-content/uploads/2017/02/A4AI-2017-Affordability-Report.pdf Date last updated: 2017.

16 World Bank. World Development Report 2016: Digital Dividends. www.worldbank.org/en/publication/wdr2016 Date last accessed: February 1, 2016

17 United Nations General Assembly. Resolution A/71/L.41. Global health and foreign policy: health employment and economic growth. www.un.org/ga/search/view_doc.asp?symbol=A/71/L.41 Date last updated: December 8, 2016.

18 World Health Organization. Digital Health for the End TB Strategy: Process Since 2015 and Future Perspectives. 7-8 Feb 2017. Meeting Report (WHO/HTM/TB/2017.02). https://apps.who.int/iris/bitstream/10665/255538/1/ WHO-HTM-TB-2017.02-eng.pdf Date last updated: 28 June 2017. 